Article

\title{
Planning Cultures in Transition: Sustainability Management and Institutional Change in Spatial Planning
}

\section{Mario Reimer}

ILS-Research Institute for Urban and Regional Development, Brüderweg 22-24, 44135 Dortmund, Germany; E-Mail: mario.reimer@ils-forschung.de; Tel.: +49-231-9051-268

Received: 28 August 2013; in revised form: 12 October 2013 / Accepted: 29 October 2013 /

Published: 5 November 2013

\begin{abstract}
This paper aims to critically review current discussions on the "reinvention" of spatial planning, postulating an all-encompassing and unproblematic shift towards new rationales, scopes, actors and instruments in planning practice. Buzzwords are, among others, "governance", "collaborative planning" and the "communicative turn". To overcome the somehow normative bias of these terms, the term "planning culture" is introduced to define a complex, multi-dimensional and dynamic institutional matrix combining formal and informal institutional patterns. Used in an analytical sense, it can help to better understand institutional change in spatial planning. Referring to recent conceptual debates about institutional transformation, the paper presents a six-stage model for institutional change in spatial planning, supporting it with an example from the Cologne/Bonn metropolitan region in Germany. The latter serves as an example for illustrating the institutional dynamics, but also the rigidities of planning cultural change. The paper concludes that a more thorough, "fine-grained" and empirically-grounded investigation of institutional transformation in spatial planning is necessary.
\end{abstract}

Keywords: spatial planning; planning culture; institutional change

\section{Introduction}

As John Friedmann convincingly argues [1], "planning is in a constant need to reinvent itself as circumstances change". However, the manifold triggers, mechanisms and directions of change (and of persistence) often remain unclear. While the literature quite convincingly emphasizes the "communicative turn" [2,3], the shift from government to governance [4] and, hence, the emergence of new planning cultures [5], recent work indicates a more skeptical view when considering the 
transformative potential of spatial planning. Da Rosa Pires et al. ([6], p. 257) point out that planning practice has "advanced on a more piecemeal basis, and available information and insights on the delivery of new approaches to planning are still scarce and fragmented. Since one should not expect an easy encroachment of new ideas in long-established cultural tissues, the learning potential of the emerging planning practices is still largely to be explored". Schmidt [7] identifies a major reluctance to make changes to the institutional framework and "classic" planning instruments in Germany, concluding that a gap exists between the more strategic approaches on a regional scale and actual practices and technologies used on the ground. Similarly, Koch [8] analyzes metropolitan areas in Switzerland, pointing out that the claimed shift from government to governance seems to be an exaggeration, as networked forms of governance need to be seen over a longer timeframe. Following his argumentation, loose governance networks might become institutionalized over time, becoming a stepping stone towards new, government-led and, thus, centralized and exclusive forms of metropolitan organization.

These three examples serve as a strong reminder that more empirical work is needed to prove and reconsider the theoretical debates related to spatial planning, its dynamics and transformative capacities. While the "grand narratives" (i.e., the "communicative turn") of changing paradigms in spatial planning mentioned above seem to represent helpful holistic approaches to understand and describe the evolution of spatial planning as a discipline in general $[9,10]$, the exact patterns of how spatial planning is practiced in different cultural, spatial, temporal and thematic contexts need to be analyzed more carefully. As regards the "reinvention" of spatial planning, it is important to focus on the diversity of spatial planning activities that cannot be captured by a universalized planning discourse [1]. Therefore, the "micro-practices" [11] need to be taken into account when it comes to answering the question of whether and how spatial planning has changed and in how far the above-mentioned "grand narratives" can be found in practice.

This paper aims at combining theoretical work on planning cultures and institutional change with empirical results from a case study in the metropolitan region of Cologne/Bonn in Germany. This region serves well to explain, in detail, the triggers, mechanisms and directions of change in spatial planning, as local stakeholders took advantage of a unique "window of opportunity" to question existing planning routines and rearrange their institutional repertoires with regard to the sustainable management of the natural and cultural landscape on a regional scale. Hence, the paper focuses on a governance perspective to sustainability transitions, trying to uncover the institutional dynamics and rigidities on the way towards sustainable management in cities and regions [12]. The paper consists of six sections. Following this introduction, a critical discussion of recent debates about changing governance patterns and the apparently emerging "new planning culture" is conducted. The third section aims at conceptualizing spatial planning as an institutionally embedded practice. In the fourth section, a conceptual model drawn from institutional theory is presented, helping to structure the empirical study in the fifth section. The concluding section summarizes the main results.

\section{Towards a New Planning Culture?}

Since the 1990s, a new planning culture has been postulated in the literature. Buzzwords are, among many others, "communicative turn" [2,3] or "collaborative planning" [13]. Following these strands of 
literature, spatial planning has changed fundamentally in at least four main dimensions, namely actors, instruments, scale and scope.

First, spatial planning is no longer to be seen as the exclusive domain of civil servants who have expert knowledge at their disposal and who solely use this knowledge in spatial planning endeavors. In many places, civil society is claiming its right to participate in spatial planning activities and voice its interests, as shown by the recent examples of Stuttgart 21 in Germany or the Gezi Park in Istanbul. Spatial planning as an exclusively "top-down"-oriented process seems to be facing serious limitations and needs to accommodate other interests right from the start, hence acknowledging the huge potential of local lay knowledge [14], as well as mediating the power of organized interest groups. Furthermore, spatial planning as a profession has to deal with the ever-rising power of economic actors and their interests and strategies that affect spatial planning in an increasingly neoliberal society [15]. All in all, the traditional relationships and boundaries between public, private and civil actors are becoming blurred, and new forms of networked governance in fragmented decision-making structures seem to have assumed a substantial role in spatial planning.

Second, the "institutional technologies" of spatial planning have changed. Traditional institutional structures (i.e., legal frameworks, administrative organization, basic and formally defined instruments for managing spatial development) face serious limitations when dealing with new spatial challenges requiring innovative and often unexplored paths [16]. Hence, experimentation becomes important in order to deinstitutionalize old routines and practices and to institutionalize new ones. It is at this point where the issue of strategic planning becomes crucial. Strategic spatial planning aims at introducing new governance arrangements, processes and instruments helping to take "decision makers, planners, institutions, and citizens out of their comfort zones and compel them to confront their key beliefs, to challenge conventional wisdom, and to look at the prospects of new ideas and 'breaking out of the box" ([17], p. 1115). In this context, Albrechts [17] introduces the term "transformative practices", which are meant to "refuse to accept that the current way of doing things is necessarily the best way; they break free from concepts, structures and ideas that only persist because of the process of continuity". Following this line of argumentation, recent strategic spatial planning episodes (the REGIONALE 2010 referred to in Section 5 being one of them) and processes of spatial strategy making [18] are creating innovative environments for experimentation within existing planning settings, which help to deal with "institutional uncertainty" [19]. While Christensen ([20], p. 83) argues that "planners hate uncertainty as much as most other people do, and they spend their working lives trying to reduce it", it can also be argued that spatial planning even needs uncertain contexts in order to reinvent itself. Strategic spatial planning offers a "window of opportunity" to critically test the routinized ways of coping with spatial challenges and to define a laboratory for change and experimentation.

Third, spatial planning activities are characterized by a "relational complexity" [21] concerning the multilevel governance processes and the need for a recombination of vertical and horizontal governance patterns in many city-regions across the world, culminating at a regional scale. The "enlargement of the urban scale" [22] calls for a redefinition of spatial responsibilities and also for new strategic alliances transcending the established territorial borders of political spaces and forming new functional networks. The latter can be seen as "soft spaces" with "fuzzy boundaries" [23], leading, in turn, to a mismatch between territorial and functional regionalization logic. Rescaling processes [24] and the predominance of regional contexts can be seen as a starting point or trigger for experimental 
learning and, hence, for innovation and change in spatial planning. New contexts help to challenge, break open and (temporarily) bypass rigid and often unmovable routines, traditions and practices, thus initiating learning and institutional innovation. According to Fürst ([25], p. 925), we can differentiate between instrumental learning and structural learning. The former "refers to behaviors, strategies and organizational devices that improve the capability to cope with external pressures (excluding changes of values/ideologies)", while the latter "implies changes of power structures, attacks values and ideologies and hence is highly political".

Fourth, the described shifting rationales in spatial planning concerning stakeholders, instruments and scales have led to a redefinition of scope. The plethora of actors participating in spatial planning endeavors results in a multiplicity of interests and knowledge forms that need to be deliberated and integrated when designing future spaces. New "collaborative rationalities" [13] compete with existing discursive realities, thereby undermining the strong position of "technical" knowledge and solely linear spatial planning logic. As others have shown [14,26], spatial planning mostly deals with "wicked" problems and rising complexity. Therefore, perfect "turn-key" solutions are not designable and realistic. Spatial planners need to realize and take into account the limited scope of their profession, becoming more open to interpretations of spatial planning as an open process of "strategic navigation" [27,28], where trial-and-error processes and experimentation with new "technologies" (i.e., with informal planning instruments) on multiple spatial scales are part of the business and where pragmatic adaptation to ever-changing circumstances is valuable and even desirable. Spatial planning can be seen as an experimental and speculative practice dealing with often unexpected elements, where planners are "enmeshed in a series of modulating networked relationships in circumstances at the same time both rigid and flexible, where outcomes are volatile; where problems are not "solved" once and for all but are rather constantly recast, reformulated in new perspectives" ([29], p. 224). Summarizing these storylines, spatial planning seems to have perfectly managed its "reinvention" [1] or, put more cautiously, its "renewal", hence bridging the gap between the ever-changing spatial challenges, on the one hand, and the institutional answers, on the other.

It is at this point that a careful reflection at least with regard to two dimensions is necessary. First, discussions on new governance forms and on collaborative, deliberative, representative and, hence, more democratic, transparent and open styles of planning are often assumed to be an essential backbone of a "new planning culture". We need to be aware that sometimes, these discussions are highly normative, trying to describe and define ways of how spatial planning should work, aiming at improving planning processes in a significant way and overcoming the closed-shop and expert-led arenas of traditional decision-making in urban and regional contexts. This normative bias is problematic insofar as it hides more analytical perspectives and approaches when dealing with planning cultures. Second, overall claims of a "new planning culture" may be too optimistic in that they seem to forget the non-transparent patterns of institutional change. Where spatial planning is institutionally embedded (see the next section), we need to bear in mind different dimensions of change, as well as path dependencies and "lock-in" effects and, therefore, being more precise when talking about changes in spatial planning. We are called on to concentrate on the "forces for change and continuity" [30], which lead to complex rearrangements and adaptations of the institutional landscape planning is operating in, against a background of persisting institutional stability. 


\section{Institutional Embeddedness of Spatial Planning}

Spatial planning is deeply embedded in institutional contexts. As Alexander rightly states, "institutions are a critical aspect of everything planners do" ([31], p. 210). He goes on to argue that all planning "takes place within a specific institutional context, or often in sets of different and varying "nested" institutional contexts as indeed do all societal activities" ([31], p. 210). The "institutional embeddedness" of spatial planning endeavors has been acknowledged by many scholars [31-34]. Nevertheless, the institutional perspective on spatial planning often results in focusing on "planning technologies", i.e., the organizational and institutional structures of spatial planning, such as planning law, administrative structures, procedures and instruments. Such a perspective is characterized by a clear focus on formal institutions only, hence emphasizing a structuralistic, legalistic and deterministic institutional view. Lowndes refers to these approaches as "old institutionalism", stating that the "new institutionalists" "concern themselves with informal conventions, as well as formal rules and structures; they pay attention to the way in which institutions embody values and power relationships; and they study not just the impact of institutions upon behavior, but the interaction between individuals and institutions" ([35], p. 1953).

The neo-institutional shift in planning sciences, emphasizing the "hidden" institutional patterns that determine spatial planning behavior under the surface of its more formal dimensions (planning laws and administrative organization, procedures and instruments) helps to shed light on planning cultures as an analytical concept (and not as a normative paradigm in theory and practice). As Othengrafen in his most recent work demonstrates, "planning is inserted into a specific cultural framework composed of interactive processes among involved actors, their cultural cognitive frames and the particular planning procedures and instruments. It consists of more than planning instruments and procedures; it is the aggregate of the social, environmental and historical conditions, describing the specific "cultural contexts' in which planning is embedded and operates" ([33], p. 23). This "aggregate" can be conceptualized as a three-dimensional analytical model of planning cultures, combining the institutional spheres of planning artifacts, planning environment and societal environment [36-38].

The planning artifacts refer to the "institutional technologies" spatial planners work with. They comprise the "usage and knowledge of tools, techniques, crafts, systems or methods of organization affecting the 'species' ability to control and adapt to their natural environment" ([39], p. 69). Planning law can be seen as the most obvious form of a planning technology, as it defines the formal parameters for spatial development. In the past, research has focused mainly on the sphere of the planning artifacts, a famous example being the comparative research on spatial planning systems across Europe [40]. The construction of homogeneous planning families or planning types based on the comparison of constitutional and legal frameworks has led to a structuralistic bias. Nadin ([41], p. 3) argues that "a focus on formal description may hide as much as it reveals", while Reimer and Blotevogel ([42], p. 10) emphasize that "it remains a matter of dispute whether planning reality is in fact fundamentally determined by its basis in law". The latter quote indicates that the planning artifacts need to be seen in their social and cultural embeddedness [43] and, therefore, in a wider institutional context.

The planning environment refers to the specific "institutional milieu" in which planning professionals are operating. Based on the "socialization" of civil servants dealing with issues of spatial development, but also of architects, geographers and other professional actors with a specific interest 
in spatial planning endeavors (entrepreneurs, consultants, estate agents), a common "ethos" of spatial planning becomes manifest and is lived. This "ethos" refers to the basic ideas, traditions and values of planning professionals. It determines the institutionalization and use of the planning artifacts in different cultural contexts.

Finally, the planning artifacts and the planning environment are embedded in a broader social context. The social status of planning is derived not only from the legal and administrative tradition, but is also dependent on individual "models of society", as "ideal types used to generalize about the diverse values and practices that shape relationships between the state, the market and citizens in particular places" ([44], p. 283). Therefore, spatial planning practices are not exclusively dependent on legal and administrative frameworks, but also on the different socio-economic, political and cultural structures and dynamics prevailing in different societies.

While we know much about the input and output dimensions in spatial planning (the former concerning the spatial challenges (i.e., demographic change, climate change or social inequalities) and their impacts on spatial structures and developments, while the latter is all about the effectiveness of "institutional technologies" in dealing with different spatial challenges), the so-called "throughput" dimension concerning contextualized planning styles, governance and communication patterns, power geographies and framing processes within certain systemic contexts remains, for the most part, a black box. In this regard, Healey states that "it is necessary to enter this 'black box' to examine the complex dynamics of actors and networks as they struggle over resource allocation, over regulatory practices and over framing ideas" ([45], p. 304).

As highlighted elsewhere [38], the somehow "static" character of the model sketched out above calls for more dynamic theoretical foundations to analyze changing planning cultures. Where the latter are understood as complex institutional matrices [30] or "institutional milieus" [46] combining formal and informal institutional spheres (see above), the link between institutional transformation and planning [31] becomes central.

\section{Planning Cultures between Stability and Change}

Understanding institutional transformation in spatial planning requires sensitivity for the institutional relations of contextualized governance dynamics. Coaffee and Healey [47] identify three intermingled levels of governance, namely, the level of episodes, the level of processes and the level of governance cultures. By episodes, the authors refer to the interpersonal relations of actors in specific institutional sites. Episodes involve "many interactions, weaving through several arenas, in which diverse actors are drawn into encounters and activities through which strategies are formulated, consolidated and diffused" ([21], p. 32). On the level of concrete processes, actors voice their interests and establish strategic networks and procedures to achieve them via certain discourses and framing processes. On the deeper level of governance cultures, the taken-for-granted habits and values of actors become relevant, as they determine the patterns of action and are themselves subject to change when practices and discourses lead to a gradual adaptation of the deeply embedded cognitive patterns of actors.

Coaffee and Healey stress the importance of the duality of structure and agency, arguing that "institutionalists with a more sociological perspective emphasize the interactions between structuring dynamics and micro-politics. They are concerned not only with how 'institutional inheritance' shapes 
future possibilities, but how new 'institutional capacities' get built” ([47], p. 1982). Thus, their conceptions are deeply rooted in sociological institutionalism, building on at least five main assumptions ([48], p. 2058): First, sociological institutionalism aims at identifying the complex and equitable interplay of formal and informal institutions. Second, the focus is primarily on the interaction of the actors and not on their decisions. Third, institutional change is a core interest. Fourth, the focus is on institutional capacity building processes, thereby promoting the active and intentional shaping of institutional patterns. Fifth, these processes are closely intertwined with issues of identity and place-making.

Particularly interesting is their hypothesis that "transformation cannot be claimed unless all three levels change significantly" ([47], p. 1983). They call for a contextualized and multi-dimensional perspective when analyzing institutional transformation and adaptation, arguing that the interplay of the levels of governance-episodes, processes and cultures is essential and that isolated and one-dimensional arguments of change are not satisfying. To illustrate this point: though it is fairly easy to identify new governance arrangements, new actors and new discursive rationales in spatial planning endeavors, these manifest changes will not tell us anything about the non-manifest and hidden interests, roles and positions "behind the scenes" and about the reasons why actors work together in new networks. Thus, when striving to explain institutional change in greater depth, we need to reveal the "rules in use" behind the "rules on paper" and to uncover the deeply embedded cultural dimensions determining planning behavior. Different paces of change need to be taken into account; hence, the difference between slow-moving and fast-moving institutions [49] comes to the fore. While institutional transformation is easier to realize at the level of processes and artifacts, i.e., the implementation of a new planning law or the proliferation of new planning instruments to cope with spatial challenges, changes of values and traditions generally take a lot more time. Therefore, different strategies of institutional transformation [50] and piecemeal adaptation as "institutional bricolage" [51] are more likely than radical institutional change.

Concerning the intentional shaping of institutions and the processes of institutional capacity building, the juxtaposition between "institutional design" and "institutional evolution" is of importance [52,53]. If we understand planning cultures as complex and multi-dimensional institutional matrices comprising manifest (formal) and non-manifest (informal) institutional spheres that need to adapt to ever-changing external and internal circumstances, the key question is whether institutional settings can be intentionally designed or whether they change unpredictably due to unintentional causes. With regard to spatial planning, the acclaimed institutional design based on rational thinking (i.e., intentional) and efficiency criteria has a long tradition. However, this linear and overtly "engineeristic" or technocratic rationale reaches its limits in times of rising complexity. Planners need to modify and adapt their claims of perfectly "ordering" space, defining and accepting new roles and positions in the complex web of actors, interests and challenges they are confronted with.

This is where a more "kosmos-oriented approach" entailing "a rejection of the presumptuous rationalistic claim that institutions can be built according to a preconceived plan" ([53], p. 284) gains currency. The process of institutional change can best be understood and analyzed when one understands the evolutionary nature of institutional settings, hence accepting their sometimes unintended dynamics and unpredictable paths. This is the reason why the claim for a new planning culture based on communication, collaboration, transparency and inclusion seems overhasty, as it implies that planners are perfectly capable of intentionally changing the institutional landscapes they 
are embedded in. Certain crucial aspects are missing in this argumentation. What about institutional rigidities that cannot be anticipated, and what about any unintentional effects of intentional actions? Additionally, what about institutional lock-in effects and the need for destabilization before the rearrangement of malleable institutional patterns can take place?

A promising link between the destabilization of robust institutional settings and institutional change is the work done by Greenwood et al. [54] and Buitelaar et al. [52], who focus on the processes of deinstitutionalization and reinstitutionalization. Greenwood et al. ([54], p. 58) claim "that little is known of how and why institutionalized practices within a field atrophy or change", while Buitelaar et al. ([52], p. 891) bemoan the lack of a "plausible theory of how institutional change actually occurs". The combination of these works is highly valuable for the field of planning research, as they present a procedural model for conceptualizing and explaining institutional change in general. The following paragraphs describe and explain their basic ideas, combining them with the issue of planning cultural change. The model serves as a foundation for the empirical material gathered in Section 5.

Following Greenwood et al. [54], institutional change can be theorized as a process comprising six stages (Figure 1). As discussed above, planning cultures are complex institutional matrices comprising formal and informal institutional spheres at a certain time and place. As such, they are in a state of equilibrium, as long as external and internal conditions are stable and actors have no need to change their ways of acting, as well as their cognitive patterns with regard to spatial planning challenges, objectives and tasks. In such "periods of stability" ([52], p. 896), the planning technologies at hand allow for a thorough handling of spatial challenges, with the goals of spatial planning remaining unquestioned. Planning is more or less a routinized procedure; the pressure for change is low. Buitelaar et al. ([52], p. 896) illustrate that the stability of existing institutional arrangements is closely connected to "discursive hegemonies" that support the way of doing things in a certain spatio-temporal context.

Where internal or external pressures for change are high (phase I), institutional arrangements become malleable. Such pressures can be societal, economic, ecological, political or technological in nature. In many cases, external pressures for spatial planning, such as climate or demographic change, challenge stable planning cultures and result in a process of institutional reflection. Actors start to question discursive hegemonies in place, paving the way for the deinstitutionalization of planning cultures. "Shock events" (sudden events with severe impacts on spatial patterns, such as moments of crisis, catastrophes, etc.) are a main driver for institutional change, allowing agents to promote institutional change from the inside. So-called "bricoleurs" ([52], p. 895) come to the fore, identifying "windows of opportunity" and actively trying to stimulate institutional change.

After breaking up existing discursive hegemonies and deeply routinized ways of thinking and acting, planners find themselves in unfamiliar contexts of uncertainty [20]. With institutional stability dissolving, planners need to readjust their planning technologies, as well as their basic cognitive frames, "circumscribed as culturally determined frameworks, perspectives, systems of meaning, paradigms or positions from which the actor or a group of actors order social reality and make sense of his or her actions" ([34], p. 93). Planners are more willing to experiment with new rationales, procedures and instruments, testing new planning technologies in new strategic alliances and networks (phase II). 
Figure 1. Planning cultures between stability and change.

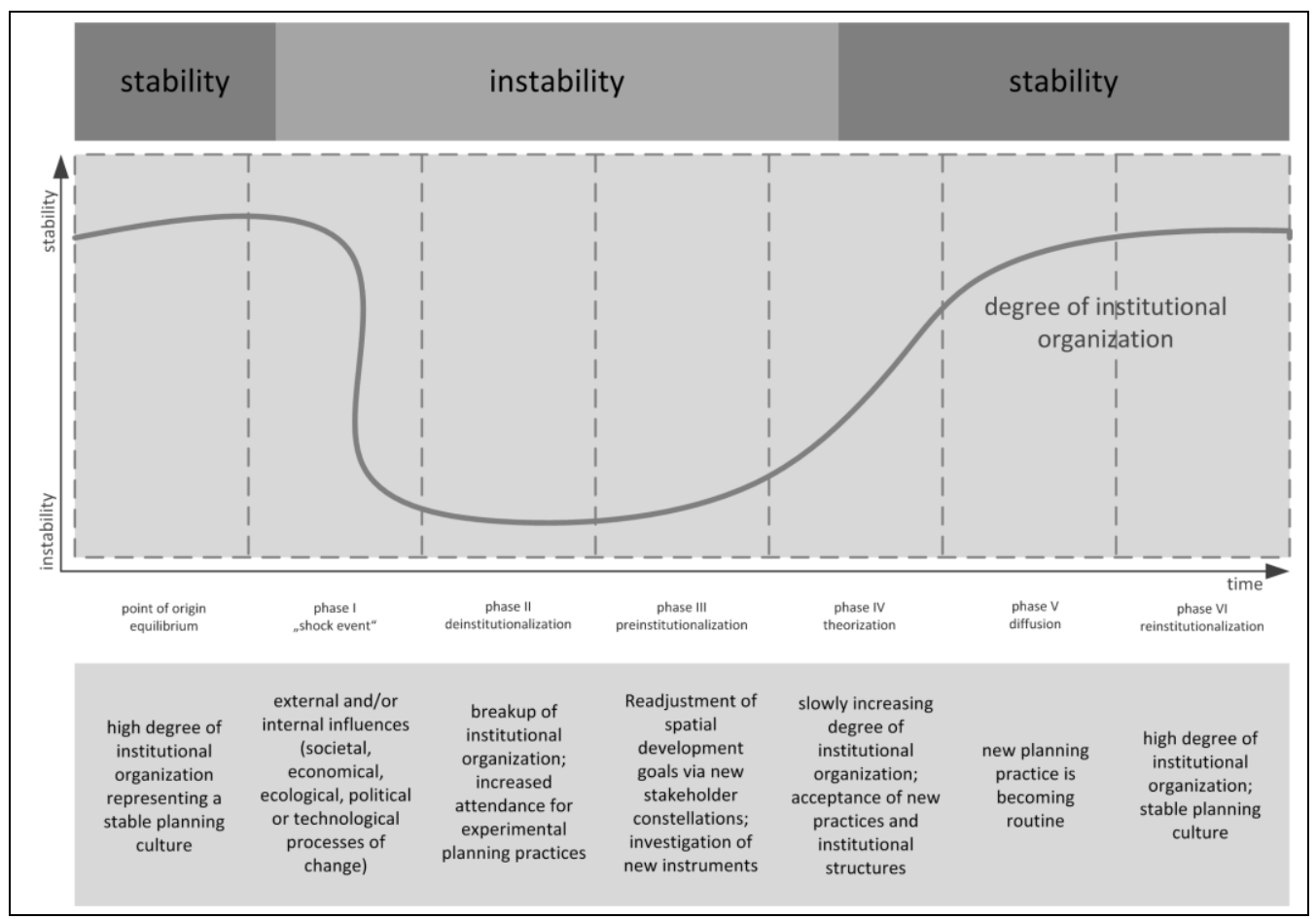

Where new rationales, procedures and instruments are successful in helping to manage spatial challenges, a gradual process of institutional rearrangement takes place (phase III). New rationales are concentrated in new "discursive hegemonies" and new instruments may replace or complement old ones. This is where institutional arrangements slowly regain stability and planning innovations become reinstitutionalized. This phase is closely intertwined with the phase of theorization (phase IV), during which the degree of institutional stability constantly increases and institutional uncertainties decrease. Instrumental and structural learning take root, and changes can become established in the deeper governance cultures.

Finally, the constant application of new rationales and instruments results in new routines, leading to a new stability of planning cultures (phase V). Organizational and cognitive institutional patterns return to a state of equilibrium. Actors accept their new roles, positions, rationales and technologies, reproducing them through planning practice and embedding them in their practical consciousness (phase VI) [55].

\section{Sustainability Management and Institutional Change: A Case Study from Germany}

In the remainder of this paper, a case study from Germany is used as an example for illustrating the institutional dynamics and rigidities of planning cultures, in accordance with the different phases mentioned above and underpinned by a number of citations from planning professionals. I refer here to the metropolitan region of Cologne/Bonn situated in the western part of Germany, comprising the cities of Cologne, Bonn and Leverkusen, as well as four surrounding counties. In total, the region comprises 53 municipalities and is often referred to as a best practice case for regional cooperation and innovative regional development in Germany. The region has a long and trustful tradition of inter-municipal cooperation. Since 1992, the regional association "Region Köln/Bonn e.V." has been responsible for issues of regional cooperation, place marketing and identity building. It serves as a 
platform and catalyst for regional initiatives and successfully bid to host the REGIONALE 2010, planning for which work started in 2002.

\subsection{The REGIONALE in North Rhine-Westphalia (NRW)}

The REGIONALE is an innovative instrument of regional development policy restricted to the federal state of North Rhine-Westphalia, based on the main principles of the International Building Exhibition (IBA) "Emscher Park" held between 1989 and 1999. Two years before the end of the IBA "Emscher Park", the NRW government recognized the specific potential of proactive regional development, at first in the form of ad hoc and project-oriented interventions intended to act as a stimulus for the internal and external perception of regional scopes of action. This led to the NRW government making the decision in 1997 to extend the principles successfully established in the Emscher Park project to other parts of the state, implementing a new structural policy instrument in the form of the REGIONALE.

Since 1997, NRW regions are in principle able to apply to organize a REGIONALE in the context of a corresponding request for proposals issued by the state government. As an instrument, the REGIONALE offers NRW regions the opportunity to discover their potential and form alliances. In doing so, the regions are called upon to establish a regional concept focused on their specific strengths and development potential. This concept then competes with concepts from other regions. REGIONALE initiatives are very much project-oriented ([56], p. 82) and involve the joint preparation, implementation and presentation of projects and initiatives with an overall regional context and aimed at boosting the region's overall profile [57]. Projects implemented in the context of a REGIONALE enjoy funding priority, with funding coming from existing NRW, federal and EU programs.

REGIONALE projects follow three basic principles. First, participation is voluntary. Both the demarcation of the region and the selection of cooperation themes are to be justified in the application. Second, one of the main aims of a REGIONALE is to boost a region's innovative capacity. The focus here can be on material innovations, for instance, in the form of new urban planning forms and qualities, but also on a long-term change in the interpretation patterns and attitudes of actors. In the latter sense, the innovation-oriented planning approach is also to be understood as "immaterial" planning. In this context, competitions play an important role, as they produce the necessary quality pressure on the road towards sustainable material and immaterial innovation in urban and regional development. Third, each REGIONALE focuses on a specific presentation year during which the projects, whether already implemented or in the course of implementation, are presented to the public. This serves not just to communicate the projects and plans externally, but also plays a major role in boosting awareness for one's own region [58].

\subsection{REGIONALE as Catalyst for Change (Phase I)}

The spatial structure of the region with its core cities, Cologne, Bonn and Leverkusen, is characterized by a still growing population, being one of Germany's growth regions and "hot spots". This results in high pressure being put on open spaces and intact natural landscapes, as urban cores expand and encroach on the remaining open spaces, one of the most urgent challenges for regional development and coordination. 
Alongside the external pressure created by the forecast urban growth and the threat of fragmented open spaces on a regional scale, the lack of a flexible, region-wide instrument to steer and coordinate landscape development was becoming increasingly obvious. Though traditional sectoral landscape planning naturally offers possibilities to protect certain areas from further development, a regional discourse on the potential of an interconnected, flexible and voluntary informal strategy that aims at enhancing regional coordination, hence defining common goals and qualities for the preservation and future sustainable development of the natural and cultural landscape, was absent.

The REGIONALE 2010 offered a unique opportunity to put the issue of regional sustainability management on the planning agenda (alongside many other issues, such as urban development or sustainable resource management). As a "window of opportunity" or "critical moment" [52], it served as a welcome opportunity to reframe existing discourses and practices and to redefine established institutional technologies for the sustainable management of existing open spaces and cultural landscapes in the region. As an episode restricted to a certain timeframe (2002 to 2010/2011) and fostering voluntary and issue-based forms of regional cooperation, it created an "experimental field", where actors were able to discuss issues, such as the management of a sustainable cultural landscape in a densely populated region in a new and creative way. Off the beaten tracks of formal municipal and regional planning, it enhanced creative thinking and framing and took advantage of its exceptional position in the existing governance landscapes.

"We really saw this REGIONALE as an opportunity. The application phase saw us putting our heads together, in the knowledge that the REGIONALE was the one and only way of thematically highlighting the themes nature and landscape" (an expert's opinion, own translation).

Of crucial importance was the establishment of a regional agency in 2003 (obligatory for all REGIONALE initiatives) as a core unit for communicating the main aims, surveying and coordinating project initiatives and networking activities. It served as a new and "external" institution on a regional scale. It gained the general acceptance of the municipalities and such regional institutions as the NRW state government and the regional planning authority and fulfilled its role as a regional "think tank" for defining a blueprint for the region's spatial future. The REGIONALE 2010 Agency took advantage of its unique and, therefore, neutral position in the existing governance landscape and was able to promote regional cooperation without risking a discussion about existing formal competences and administrative borders.

"Within this process, I felt that it was a great advantage to have the REGIONALE 2010 Agency, with its top-notch staff, as the central point of contact. It wasn't just one of the participants who had practically been forced to assume control; it functioned as an independent organ, able to interact with any level of government, from the local mayor to state ministers, a very important aspect allowing us to really get things moving within a reasonable period of time. Otherwise, you just end up with statements of good will. Even the best agreements can fail to materialize without such an agency" (an expert's opinion, own translation).

In the initial phase, the REGIONALE 2010 served well as an instrument for defining spatial challenges and getting them onto political and planning agendas, hence fostering a "spirit of 
cooperation". However, to use the words of Buitelaar et al. [52], a "critical moment" needs to be converted into a "critical juncture", breaking with past patterns and learning new ones.

\subsection{Breaking with the Past? The Revival of "Sleepy" Networks and Spatial Visions (Phase II)}

The deinstitutionalization of existing institutional arrangements is a prerequisite for institutional transformation. The REGIONALE 2010 offered a unique opportunity to define and establish new regional alliances and strategic networks, as well as new spatial images for regional development. After being nominated by the federal state of North Rhine-Westphalia in 2002 as the host region for the REGIONALE 2010, the "Region Köln/Bonn e.V." intensified the discussion on thematic fields suitable for regional cooperation. As an already existing regional association, the "Region Köln/Bonn e.V." comprised different working groups, one of them concerned with the issues of nature und landscape (the "Nature and Landscape" working group). This working group had existed since the mid-1990s, its members coming from the big cities of Cologne, Bonn and Leverkusen, as well as from the participating counties and other institutions relevant for the development of the cultural landscape. Identifying the REGIONALE as a chance to realize its main aims and objectives, the working group intensified its link to the REGIONALE 2010 Agency, exchanging ideas about possible ways of working together. Before the REGIONALE 2010 became anchored in the region, the working group had been less active, i.e., the REGIONALE provided the necessary momentum and motivation to reactivate a "sleepy" network.

"I was getting the impression that it was nothing more than a nice circle, meeting for coffee and cakes once or twice a year, to talk shop without really stepping on anyone's foot, and finally to arrive at a broad consensus without any real results relevant to planning" (an expert's opinion, own translation).

The working group served as an initial platform for thematic debate on the region's natural and cultural landscape. At the beginning of this process, the definition of an image or vision for the region was of crucial importance. This helped "channel" the perceptions and interests of actors and communicate planning ideas to the political spheres. In many cases, politicians, but also civil society, need simple, "easy-to-grasp" and abstract visions, as spatial planning often deals with complex matters and technical issues not easy to understand as a lay person.

After discussing several ideas on how to go about developing the region's landscape, the actors came up with the idea of a new regional green belt. Rooted in the concepts for Cologne's inner and outer green belts developed in the 1920s under Konrad Adenauer and Fritz Schumacher, the idea of a third green belt on a regional scale proved to be a suitable concept for illustrating and communicating the working group's main ideas concerning the natural and cultural landscape. This idea worked well and was supported by all actors. One of the main reasons for this was that the concept of Cologne's inner and outer green belts being deeply rooted in planning discourse and history, hence politically accepted in the region.

"If I remember rightly, the idea to have a third green belt around Cologne first cropped up in the mid-1990s in the context of the local elections. If you look at Cologne, you'll see that everything to 
do with urban development, ever since the time Adenauer was mayor, has always been given a positive reception, regardless of party boundaries" (an expert's opinion, own translation).

It can be seen that the actors intentionally resorted to established spatial concepts. In this sense, the idea of a third green belt is to be understood as a "floating concept" that was filled with new life in the course of the REGIONALE 2010, i.e., an initially local planning doctrine has developed over the decades into a spatial vision for the whole region.

\subsection{New Planning Technologies and Strategic Networks: The "Master Plan Green" (Phases III and IV)}

The Cologne/Bonn region is to be seen as a highly dynamic urban landscape. The forecasted increase in the population is leading to appreciable urbanization, putting major pressure on land use within the region, and this is one of the main reasons why innovative and, above all, flexible regional development instruments based on integrated development and opening up of future potential are so important.

After having come up with a "catchy" spatial vision, which helped to frame and communicate the main idea of a cohesive and sustainable landscape in the highly urbanized Cologne/Bonn region and after the strategic consolidation of the REGIONALE 2010 Agency and the working group, these main "actors for change" or "bricoleurs" decided to develop a new master plan. Since 2004, the "Nature and Landscape" working group has been and still is responsible for developing and updating the so-called "Master Plan Green" in close cooperation with the REGIONALE 2010 Agency (though the REGIONALE 2010 Agency has, in the meantime, been dissolved, the master plan remains a core document in the responsibility of the working group and the "Region Köln/Bonn e.V."). This master plan is an informal and strategic instrument describing and analyzing the region's different cultural and natural landscape types and potential in the region as the first step. It covers different sectorial perspectives and issues, such as urban development, water management, cultural heritage, climate change, agriculture, forestry or recreation and, thus, helps to find a common perspective and boost awareness for the necessity of integrated sustainability management. It further clearly points to expectable conflicts and formulates guiding principles for the sustainable management of the region's landscape.

As an informal instrument with no legally binding power, the master plan can be interpreted as a new planning instrument complementing such formal instruments as land use plans, regional plans or landscape plans. Bearing witness to the region's great self-confidence, the master plan contains a strategic development perspective, not just presenting a sustainable regional development Leitbild, but also contributing to increased process quality. This has meant that the master plan and its compilation dictated the REGIONALE process from the word "go", uniting actors on the strategic level in a regional discourse.

One of its main features is its great flexibility. It is regularly updated, allowing account to be taken of current spatial development challenges (e.g., climate change). Currently, the master plan is in its third version. It is this flexibility and its somewhat informal character that provide it with its great potential as a meaningful supplement to formal planning. Though not intended as a replacement for existing forms of formal regional planning, the master plan is, however, an incentive for a discourse on regional development objectives centered on a Leitbild. The master plan supplements formal planning instruments insofar as it provides them with a "strategic vision component" ([59], p. 45). 
The "Master Plan Green" is often referred to as a symbol of a new planning culture. Its informal and flexible character is seen as an advantage when compared to traditional and sometimes languid technologies of spatial planning.

"In my mind, the master plan and the initial discussion regarding its creation revealed a new dimension. Right from the word "go", the master plan was seen as a bilateral instrument, developed on a voluntary basis and intended to serve a large group of public authorities as a guideline and as a basis for official planning measures, in accordance with their statutory planning responsibilities. With the local authorities — the "Kommunen"-having this statutory planning responsibility, the REGIONALE and the master plan are nothing more than a supporting instrument. The attempt has been made to set forth general principles applying to the region and beyond. These are then taken into consideration on a voluntary basis" (an expert's opinion, own translation).

The "Master Plan Green" has stimulated networking within the region, whereby two different types of networking can be distinguished. First, horizontal networking between different municipalities has resulted in a strong commitment towards a collaborative strategy for the sustainable management of the natural and cultural landscape on a regional scale. Due to the unceasing efforts of the REGIONALE 2010 Agency and the "Nature and Landscape" working group, the purpose of the master plan as a strategic vision for the region has been communicated in all 53 participating municipalities. The general idea and use of the master plan have been conveyed to both planning officials and politicians. Both groups were important as the strategy gained momentum and became an established topic on planning and political agendas throughout the whole region. The horizontal networking helped to create a strong regional identity and enhanced collaborative and inter-municipal strategies.

"No, the idea about working together just didn't crop up beforehand. Planning issues always stopped at local authority boundaries " (an expert's opinion, own translation).

Second, there was vertical networking "behind" the "Master Plan Green", enabling individual and, above all, small municipalities to strengthen their links to important actors and institutions at higher levels. This is an important aspect, as it led to a significant increase in the strategic capacities of individual municipalities. The REGIONALE 2010 Agency served as a mediator between individual municipalities and key actors in ministries and public authorities, transgressing hierarchical boundaries and providing access to ministries, high-ranking politicians and funding institutions for individual projects.

"We now suddenly see that we have a great opportunity to get things done, things which we had previously not seen and which we were unable to realize for the simple reason that we had not seen them in the wider context. (...) You need to make deliberate use of the set of instruments. I can now get things done which were previously impossible. Although they are good and meaningful, this was not the case when they were looked at separately. I would have never been able to sell such ideas " (an expert's opinion, own translation).

A further interesting aspect is the central position held by the REGIONALE 2010 Agency and the "Nature and Landscape" working group, with clearly defined rules for participating in the master plan development process. In its composition, the "Nature and Landscape" working group was more 
focused on actors from the administrative side, with only minor account being taken of private and civil society interests in the form of direct personal participation. The group thus defined a playing field characterized by a very limited and selective permeability, thereby having a high entry barrier. Leitbild design with regard to the development of the region's natural and cultural landscape thus remained in the hands of a small strategic elite. As a way of maintaining the group's working ability, the concrete decision was taken not to permanently expand the network of actors.

"The composition of the working group was clearly defined, with representatives from the counties and cities being included. We also included representatives from the nature parks, even if they didn't all turn up. And the "Landschaftsverband", the main body responsible in this area, was also a member. And that's where it ended, i.e., our 53 municipalities never had any chance of getting involved. If we had done that, we would have ended up with a huge group" (an expert's opinion, own translation).

\subsection{Facing the Limits of Institutional Transformation (Phases V and VI)}

Following Healey, "to have transformative effects, governance innovations (such as new discourses, new allocatory or regulatory practices, the formation of new arenas or networks) must move from explicit formation episodes to arenas of investment and regulatory practice. To endure, they have to become institutionalized in the routines of governance practices. (...) New concepts have to challenge and shift an array of already routinized governance processes, with their complex mixture of conscious and taken-for-granted modes of practice. New concepts have to "jump" boundaries and "breakthrough" resistances, involving implicit and explicit struggles" ([45], p. 305).

The intersection of the phases of "preinstitutionalization/theorization" and "diffusion" is where the full picture of institutional transformation becomes clear. As the previous sections show, the REGIONALE 2010 acted as a trigger for experimentation, enhancing new spatial discourses and frameworks, instruments and networks. In the following, the depth of institutional transformation will be explored, taking into account not only the effects of instrumental learning, but also of structural learning. As the REGIONALE was an episode limited to the 2002-2010/2011 period, one of its main challenges has been to "routinize" innovative discourse and practices and make them sustainable, thus becoming part of the planners' deeper and unconscious cognitive patterns and guiding planning practice after the end of the REGIONALE 2010.

Institutional transformation in spatial planning involves breaking with the past and readjusting existing institutional patterns. In the case of the REGIONALE 2010, the informal "Master Plan Green" is an important step towards a new planning culture at regional level. Assessing whether the master plan ("rules on paper") really reflects any deeper transformation of planning routine requires a closer look at the relationship between informal and formal spatial planning instruments. It is at this juncture that discursive and instrumental changes (new spatial frames and new planning instruments) find their place in existing institutional frameworks and, thus, form the complex institutional amalgamations Scott refers to in stating that institutions "do not emerge in a vacuum; they always challenge, borrow from, and, to varying degrees, displace prior institutions" ([60], p. 95).

In this sense, the master plan challenges existing formal rules and procedures, such as the regional spatial structure plan in force for the administrative district of Cologne or the state development plan 
for North Rhine-Westphalia. It seems that the "spirit" of the "Master Plan Green" has penetrated the formal spheres of spatial planning, with the latest (third) version clearly stating that both the next regional spatial structure plan and the new version of the state development plan will carefully consider its main aims and findings. This is a distinct indication of institutional transformation, reaching down to the deeper layers of planning cultures as described above. However, it is also interesting that the master plan underlines the importance of flexibly interlocking formal and informal processes, explicitly stating that it (the master plan) is not to be formalized in itself, thereby highlighting its outstanding position and maintaining its status as a unique piece of work.

Nevertheless, instrumental and structural learning is limited. It seems as if Healey is right in saying that it is not easy to "jump" boundaries and "breakthrough" resistance. Though the master plan serves as a spatial frame for the Cologne/Bonn metropolitan region, its realization and spatial "effectiveness" are dependent on formal local-level frameworks. Each municipality is responsible for its spatial development. It may decide to voluntarily take into account the main goals and interests formulated in the master plan, though only the local-level formal instruments are legally binding, e.g., land use plans. The success of regional visions is therefore dependent on the willingness of local actors to integrate regional principles. This is a classical problem of "jumping scales", i.e., linking regional and local interests, not just as rhetorical commitments, but also in practice.

"The master plan can obviously be seen as a connecting link. But, when you are more concerned with local topics, these will always take precedence over any consideration of the next level upwards. As is so often the case with such a master plan with its overall concepts, when you get down to the details, it is often ignored" (an expert's opinion, own translation).

The second point mentioned by Healey is the need to "break through" resistance. Such resistance is often deeply rooted in cognitive patterns and ways of framing and filtering reality. In the case of the REGIONALE 2010 and the "Master Plan Green", the strategic alliance between planners and politicians was of crucial importance. One difficulty experienced on the road to a regional awareness was that it was difficult at the start to gain basic political understanding for the whole idea of jointly developing the natural and cultural landscape. It turned out to be difficult to integrate the politicians at the start in the overall process (political resistance). If anything, the REGIONALE 2010 process has revealed the tension between planning and politics. Based on persisting local authority egoism, this tension imposed limits on the process. Whereas the "Master Plan Green" puts across the vision of a regionally coordinated plan, a look behind the "rules on paper" reveals the persistence of a latent parochial thinking rooted in local politics.

"Yes, of course we still have parochial thinking. There's no question about that. And in my mind, there are also serious reservations regarding the regional idea, because it just isn't clear where the journey is taking us. Are we going to end up with a new metropolitan region? Are we going to end up with the removal of certain administrative structures? Are we even going to end up with the disappearance of certain municipalities within the counties? These are all concrete fears. People don't like having to give something up" (an expert's opinion, own translation).

Finally, the relationship between institutional design and institutional evolution plays a crucial role. Whereas the REGIONALE can be used as an instrument enabling actors to break with routine and 
experiment with new instruments, thus by-passing existing structures for a certain time in the "shadows of hierarchy", the outcomes of experimental regionalism are not foreseeable. This becomes obvious in the case of the REGIONALE 2010, where far-reaching and unplanned institutional transformations occurred during the process. One example was the transformation of structural conditions relevant for the granting of financial funds. It became obvious that established ways for accessing funding did not function well in an urbanized region where cities and open spaces were increasingly merging into each other. With funds traditionally granted either for urban areas or open spaces, this meant that many projects were not fully eligible, as the spatial concepts did not match the allocation principles of the existing funds. The REGIONALE 2010 Agency did a fair bit of lobbying work, prodding the relevant ministries and regional authorities to adapt financial structures. This led to the gradual metamorphism of funding guidelines in the field of nature conservation. During the REGIONALE 2010 process, the critical discussion of restrictive funding structures stimulated learning processes between different ministries and regional authorities, leading to a gradual, but unplanned, adaptation, proof of unintended and evolutionary institutional change.

\section{Final Remarks}

The "reinvention" of spatial planning is a complex matter. Referring to current debates on new planning cultures, I have tried to point out their highly normative character and the need to put such theoretical debates to the test in a critical manner, i.e., arguing that they should be contested and enriched with empirical studies that help to overcome their normative stance. Collaboration, transparency and legitimacy are first and foremost normative terms strongly related to the governance debate (itself often used as a normative concept), somehow characterizing a "good" planning culture needing to be implemented and lived in different contexts. However, as others have argued [61], normative approaches clearly face limits when it comes to explaining and analyzing the "real world" of planning activities, as they have the potential to prevent an unprejudiced perspective of the observer.

If we take institutional theory seriously [35] and follow the more sociologically grounded institutional approaches proposed in this paper, planning cultures can be conceptualized as complex and dynamic institutional matrices combining formal and informal institutional spheres. They are multi-dimensional, consisting of different "layers" that need to be uncovered. Whereas a body of insightful work on conceptual models has been slowly disseminated over the last few years and has acted as a useful starting point for this paper, the issues of institutional transformation and the dynamics of planning cultures are still rarely taken up. To overcome this disparity, planning cultures have been conceptualized as institutional matrices and linked to theories of institutional change.

Empirical results from the Cologne/Bonn metropolitan region show that the REGIONALE 2010 "episode" served as a trigger for change. From 2001 onwards, planning professionals in the region had the unique opportunity to experiment with new spatial rationales and instruments, the "Master Plan Green" being a prominent artifact and symbol of planning cultural change. However, as has also been shown, analyzing the level of planning artifacts alone is not sufficient when the "rules in use" behind the "rules on paper" are taken into account. Though the REGIONALE 2010 clearly stimulated change on the procedural level of spatial planning, i.e., new types of horizontal and vertical networking or the formation of new strategic alliances for change (e.g., the link between the REGIONALE 2010 Agency 
and the "Nature and Landscape" working group), the deeper level of planning cultures was only partially affected. It is interesting to note that experimental regionalism faces a "critical juncture" when it comes to the intersection of informal and formal ways of planning, when innovations need to be routinized (as the example of the "Master Plan Green" has demonstrated) and transferred into everyday life, hence affecting the "beliefs", "traditions" and social construction of institutions in a certain spatio-temporal context [62].

Coming back to the "grand narratives" of the "reinvention" or "renewal" of spatial planning, this paper aimed at a more contextualized and careful interpretation of such. It seems overhasty to identify a massive and all-encompassing change, hence assuming a shift from elitist and top-down planning circles to collaborative, bottom-up and well-balanced multi-actor constellations, from formal to informal instruments and procedures, from fixed administrative regions to "soft spaces" with "fuzzy boundaries" and from a technocratic rationale of spatial planning to open-ended "strategic navigation". Institutional transformation follows multiple paths of change and continuity. As has been shown, supposedly new instruments, new networks and new spatial frameworks, such as the "Master Plan Green" have their roots in history. The latter is built on existing concepts, adapting them to current needs (as the vision of a third regional green belt has shown). Furthermore, the purposeful design of institutional change is at least questionable. As shown, spatial planning endeavors, such as the REGIONALE 2010 in the Cologne/Bonn metropolitan region, can only generate creative environments for change. Planners have to accept that outcomes are volatile and that some institutional innovations just happen. A central task is the identification of occasions for change and the acceptance of uncertainty as a prerequisite for learning; the door to institutional innovation is above all open in situations "in which the actors act under conditions of uncertainty and where negotiating positions are unclear at the start, instead being defined during negotiations and possibly subject to interpretation" ([63], p. 299, own translation).

\section{Conflicts of Interest}

The author declares no conflict of interest.

\section{References}

1. Friedmann, J. Planning Cultures in Transition. In Comparative Planning Cultures, Sanyal, B., Ed.; Routledge: London, UK, 2005; pp. 29-44.

2. Healey, P. Planning through debate: The communicative turn in planning theory. Town Plann. Rev. 1992, 2, 143-162.

3. Healey, P. The communicative turn of planning theory and its implications for spatial strategy making. Environ. Plann. Plann. Des. 1996, 2, 217-234.

4. Pierre, J.; Peters, B.G. Governance, Politics and the State; Palgrave Macmillan: Basingstoke, UK, 2000.

5. Ludwig, J. Die neue Planungskultur in der Regionalentwicklung-eine Spurensuche. Raumforsch. und Raumordnun. 2005, 5, 319-329. 
6. Da Rosa, P.A.; Albrechts, L.; Alden, J. Conclusions: Driving Forces for Institutional Change. In The Changing Institutional Landscape of Planning; Albrechts, L., Alden, J., da Rosa P.A., Eds.; Ashgate: Farnham, UK, 2001; pp. 257-267.

7. Schmidt, S. Land Use Planning Tools and Institutional Change in Germany: Recent Developments in Local and Regional Planning. Eur. Plan. Stud. 2009, 12, 1907-1921.

8. Koch, P. Overestimating the Shift from Government to Governance: Evidence from Swiss Metropolitan Areas. Governance 2013, 3, 397-423.

9. Albers, G. Über den Wandel im Planungsverständnis. RaumPlanung 1993, 61, 97-103, (in German).

10. Hudson, B.M. Comparison of current planning theories: Counterparts and contradictions. J. Am. Plann. Assoc. 1979, 4, 387-398.

11. Healey, P. Introduction to Part One. In The Ashgate Research Companion to Planning Theory: Conceptual Challenges for Spatial Planning; Hillier, J., Healey, P., Eds.; Ashgate: Farnham, UK, 2010; pp. 37-55.

12. Frantzeskaki, N.; Loorbach, D.; Meadowcroft, J. Governing societal transitions to sustainability. Int. J. Sustainable Development 2012, 15, 19-36.

13. Innes, J.E.; Booher, D.E. Planning with Complexity. An. Introduction to Collaborative Rationality for Public Policy; Routledge: Abingdon, UK, 2010.

14. Gollagher, M.; Hartz-Karp, J. The Role of Deliberative Collaborative Govenrance In Achieving Susainably Cities. Sustainability 2013, 5, 2343-2366.

15. Waterhout, B.; Othengrafen, F.; Sykes, O. Neo-liberalization Processes and Spatial Planning in France, Germany, and the Netherlands: An Exploration. Plann. Pract. Res. 2013, 1, 141-159.

16. Albrechts, L. Creativity in and for planning. disP Plann. Rev. 2005, 162, 14-25.

17. Albrechts, L. More of the same is not enough! How could strategic spatial planning be instrumental in dealing with the challenges ahead? Environ. Plann. Plann. Des. 2010, 6, 1115-1127.

18. Healey, P. In Search of the "Strategic" in Spatial Strategy Making. Plann. Theor. Pract. 2009, 4, 439-457.

19. Allmendinger, P.; Tewdwr-Jones, M. Spatial dimensions and institutional uncertainties of planning and the 'new regionalism'. Environ. Plann. C Govern. Pol. 2000, 6, 711-726.

20. Christensen, K.S. Coping with uncertainty in planning. J. Am. Plann. Assoc. 1985, 1, 63-73.

21. Healey, P. Urban Complexity and Spatial Strategies. Towards A Relational Planning for Our Times; Routledge: Abingdon, UK, 2007.

22. Salet, W.; Thornley, A. Institutional Influences on the Integration of Multilevel Govcernance and Spatial Policy in European City-Regions. J. Plan. Educ. Res. 2007, 2, 188-198.

23. Allmendinger, P.; Haughton, G. Soft spaces, fuzzy boundaries, and metagovernance: the new spatial planning in Thames Gateway. Environ. Plann. 2009, 3, 617-633.

24. Brenner, N. New State Spaces. Urban Governance and the Rescaling of Statehood; Oxford University Press: Oxford, UK, 2004.

25. Fürst, D. The Role of Experimental Regionalism in Rescaling the German State. Eur. Plan. Stud. 2006, 7, 923-938.

26. Schönwandt, W.L. Planung in der Krise? Theoretische Orientierungen für Architktur, Stadt- und Raumplanung (in German); Kohlhammer: Stuttgart, Germany, 2002. 
27. Wiechmann, T. Planung und Adaption. Strategieentwicklung in Regionen, Organisationen und Netzwerken (in German); Verlag Dorothea Rohn: Dortmund, Germany, 2008.

28. Van Wezemael, J. Zwischen Stadtplanung und Arealentwicklung: Governance-Settings als Herausforderung für die Planung. STANDORT, Zeitschrift für Angewandte Geographie 2010, 2, 49-54, (in German).

29. Hillier, J. Stretching Beyond the Horizon: A Multiplanar Theory of Spatial Planning and Governance; Ashgate: Aldershot, UK, 2007.

30. Lowndes, V. Something new, something old, something borrowed... How institutions change (and stay the same) in local governance. Pol. Stud. 2005, 26, 291-309.

31. Alexander, E.R. Institutional Transformation and Planning: From Institutionalization Theory to Institutional Design. Plann. Theor. 2005, 4, 209-223.

32. Reimer, M. Planungskultur im Wandel: Das Beispiel der REGIONALE 2010 (in German); Verlag Dorothea Rohn: Dortmund, Germany, 2012.

33. Othengrafen, F. Uncovering the Unconscious Dimensions of Planning: Using Culture as a Tool to Analyse Spatial Planning Practices; Ashgate: Farnham, UK, 2012.

34. Ernste, H. Framing Cultures of Planning. Plann. Pract. Res. 2012, 1, 87-101.

35. Lowndes, V. Rescuing aunt Sally: Taking institutional theory seriously in urban politics. Urban. Stud. 2001, 11, 1953-1971.

36. Knieling, J.; Othengrafen, F. En Route to a Theoretical Model for Comparative Research on Planning Cultures. In Planning Cultures in Europe. Decoding Cultural Phenomena in Urban and Regional Planning; Knieling, J., Othengrafen, F., Eds.; Ashgate: Farnham, UK, 2009; pp. 39-62.

37. Othengrafen, F. Spatial planning as expression of culturised planning practices: The examples of Helsinki, Finland and Athens, Greece. Town Plann. Rev. 2010, 1, 83-110.

38. Othengrafen, F.; Reimer, M. The embeddedness of planning in cultural contexts: theoretical foundations for the analysis of dynamic planning cultures. Environ. Plann. 2013, 6, 1269-1284.

39. Janin Rivolin, U. Planning Systems as Institutional Technologies: a Proposed Conceptualization and the Implications for Comparison. Plann. Pract. Res. 2012, 1, 63-85.

40. Newman, P.; Thornley, A. Urban planning in Europe: International competition, national systems, and planning projects; Rouledge: London, UK, 1996.

41. Nadin, V. International Comparative Planning Methodology: Introduction to the Theme Issue. Plann. Pract. Res. 2012, 1, 1-5.

42. Reimer, M.; Blotevogel, H.H. Comparing Spatial Planning Practice in Europe: A Plea for Cultural Sensitization. Plann. Pract. Res. 2012, 1, 7-24.

43. Hohn, U.; Neuer, B. New Urban Governance. Eur. Plan. Stud. 2006, 3, 291-298.

44. Stead, D.; Nadin, V. Planning cultures between models of society and planning systems. In Planning Cultures in Europe. Decoding Cultural Phenomena in Urban and Regional Planning; Knieling, J., Othengrafen, F., Eds.; Ashgate: Farnham, UK, 2009; pp. 283-300.

45. Healey, P. Transforming governance: Challenges of institutional adaptation and a new politics of space. Eur. Plan. Stud. 2006, 3, 299-320.

46. DiGaetano, A.; Strom, E. Comparative urban governance: An integrated aproach. Urban Aff. Rev. 2003, 3, 356-395. 
47. Coaffee, J.; Healey, P. 'My Voice: My Place': Tracking Transformations in Urban Governance. Urban. Stud. 2003, 10, 1979-1999.

48. González, S.; Healey, P. A Sociological Institutionalist Approach to the Study of Innovation in Governance Capacity. Urban. Stud. 2005, 11, 2055-2069.

49. Roland, G. Understanding institutional change: Fast-moving and slow-moving institutions. Stud. Comp. Int. Dev. 2004, 4, 109-131.

50. Crouch, C.; Farrell, H. Breaking the path of institutional development? Alternatives to the new determinism. Ration. Soc. 2004, 1, 5-43.

51. Lanzara, G.F. Self-destructive processes in institution building and some modest countervailing mechanisms. Eur. J. Pol. Res. 1998, 1, 1-39.

52. Buitelaar, E.; Lagendijk, A.; Jacobs, W. A theory of institutional change: illustrated by Dutch city-provinces and Dutch land policy. Environ. Plann. 2007, 4, 891-908.

53. Moroni, S. An evolutionary theory of institutions and a dynamic approach to reform. Plann. Theor. 2010, 4, 275-297.

54. Greenwood, R.; Suddaby, R.; Hinings, C.R. Theorizing change: The role of professional associations in the transformation of institutionalized fields. Acad. Manage. J. 2002, 1, 58-80.

55. Giddens, A. The Constitution of Society: Outline of the Theory of Structuration.; Polity Press: Cambridge, UK, 1984.

56. Beierlorzer, H. The Regionale: A Regional Approach to Stabilizing Structurally Weak Urban Peripheries Applied to the southern fringe of the Metropolitan Area Rhine-Ruhr. disP Plann. Rev. 2010, 2, 80-88.

57. Danielzyk, R.; Panebianco, S. Die regionalen in NRW. Ziele, Strukturen, Perspektiven. Planerin 2006, 4, 25-27, (in German).

58. Danielzyk, R.; Kemming, H.; Reimer, M. Die REGIONALEN in NRW-Impulse der IBA Emscher Park. In Internationale Bauausstellung Emscher Park: Impulse. Lokal, Regional National (in German); Reicher, C., Niemann, L., Uttke, A., Eds.; Klartext Verlag: Essen, Germany, 2011; pp. 276-284.

59. Beckord, C.; Petzinger, T. Masterpläne: Ausdruck eines veränderten Planungsverständnisses. Eine Bestandsaufnahme am Beispiel des Ruhrgebietes. Raumplanung 2010, 48, 41-45, (in German).

60. Scott, W.R. Institutions And Organizations; Sage: Thousand Oaks, CA, USA, 2001.

61. Nuissl, H.; Heinrichs, D. Fresh Wind or Hot Air-Does the Governance Discourse Have Something to Offer to Spatial Planning? J. Plan. Educ. Res. 2011, 1, 47-59.

62. Krueger, R.; Gibbs, D. Competitive global city regions and 'sustainable development': an interpretative institutionalist account in the South East of England. Environ. Plann. 2010, 42, 821-837.

63. Zimmermann, K. Regional Governance als Kollektiver Lernprozess? In Regional Governance. Steuerung, Koordination und Kommunikation in Regionalen Netzwerken als Neue Formen des Regierens Band 2 (in German); Kleinfeld, R., Plamper, H., Huber, A., Eds.; V\&R unipress: Osnabrück, Germany, 2006; pp. 289-303.

(C) 2013 by the authors; licensee MDPI, Basel, Switzerland. This article is an open access article distributed under the terms and conditions of the Creative Commons Attribution license (http://creativecommons.org/licenses/by/3.0/). 